Research Article

\title{
Study of Seismic Behavior of RC Beam-Column Joints Strengthened by Sprayed FRP
}

\author{
Zhao Yang $(D$, Yong Liu, and Jiajia Li \\ Institute of Urban Construction, Wuhan University of Science and Technology, Wuhan 430065, China \\ Correspondence should be addressed to Zhao Yang; yzwh77@163.com
}

Received 19 October 2017; Revised 20 January 2018; Accepted 24 January 2018; Published 14 March 2018

Academic Editor: Renal Backov

Copyright (c) 2018 Zhao Yang et al. This is an open access article distributed under the Creative Commons Attribution License, which permits unrestricted use, distribution, and reproduction in any medium, provided the original work is properly cited.

To study the seismic behavior of RC beam-column joints strengthened with sprayed FRP, five 1:2 reduced-scale specimens of joints were tested through quasi-static experiments. The failure modes, hysteretic curves, skeleton curves, strength, deformation, degradation of strength and stiffness, ductility, and energy dissipation capacity were studied. Furthermore, the effect of three main influencing factors including the sprayed FRP thickness, strengthened area, and axial compression ratio was analyzed in this paper as well. The results show that sprayed FRP strengthening can improve the seismic behavior of RC beam-column joints effectively. The increase of sprayed FRP thickness can lead to a better seismic performance for the joints. Strengthening area can affect the bearing capacity obviously. Higher axial compression ratio can increase the bearing capacity and initial stiffness, but it can make the deformation capacity and ductility decreased. The study can provide references to further research on the sprayed FRP material for strengthening of RC beam-column joints.

\section{Introduction}

Numerous researches have been carried out on reinforced concrete (RC) beam-column joints strengthened by fiberreinforced polymer (FRP) for decades. Researches show that the FRP strengthening technology for RC beam-column joints can effectively improve the seismic performance of the joints without obviously increasing self-weight or volume [1-8], and this technology has the advantages of high strengthto-weight ratio, convenience in construction, and excellent corrosion resistance as well. However, the main forms of FRP materials are sheets and plates, which are usually externally bonded on the surfaces of beam-column joints. Such an external bonding method still has some disadvantages. The first is that the core areas of joints cannot provide enough flat surfaces for FRP to be bonded continuously, and it is difficult for such forms of FRP to wrap them efficiently. The second is that some additional processes were needed to help FRP play its role, such as drilling, bolt fixing, and adding connectors, which will increase the difficulty of construction and result in some damage in the joints sometimes. In addition, due to the complicated loading condition of joints, multilayer FRP must be bonded along different stress directions, which will lead to an increasing consumption of FRP and make the construction more complicated. These disadvantages have made a serious negative influence on the development and application of FRP used in joint reinforcement. Therefore, it is necessary to explore and study some new FRP strengthening technologies for beam-column joints.

To solve the disadvantages mentioned above, an advanced strengthening method using sprayed FRP is suggested in this paper. Sprayed FRP is a new kind of FRP consisting of randomly oriented reinforcing fibers in a matrix. Spray operation was conducted through special equipment [9]. Resins and chopped short fibers were sprayed onto the structure surface and mixed together to form a layer of continuous reinforcement materials with good mechanical behaviors. And due to the randomly oriented reinforcing fibers, sprayed FRP is an isotropic material [10]. Compared with the external bonded FRP used to strengthen beam-column joints, the sprayed FRP does not need any special materials to level the uneven concrete surface [11]. Therefore, the bonding between sprayed FRP and structures will be more direct and simplified, which can lead to a better bonding quality and an easier 


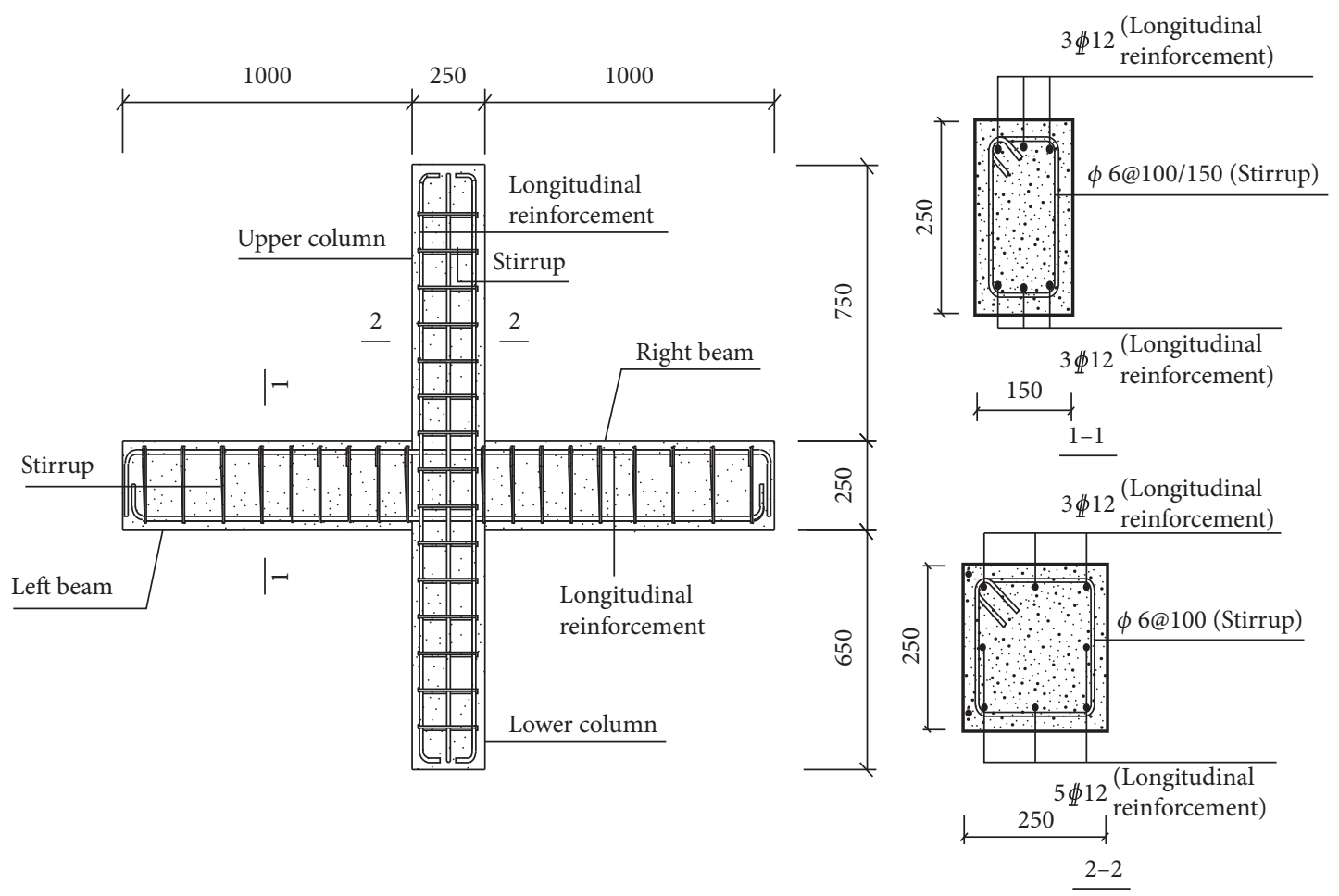

FIGURE 1: Details of the joint specimens.

construction process. Furthermore, the spraying method and the isotropic material behaviors make it possible for sprayed FRP to form a solid and continuous reinforcement layer to wrap the core areas of the joints efficiently. This kind of continuous reinforcement can be formed on not only 2-dimensional joints but also 3-dimensional ones [12]. In the situation that the column size is much bigger than that of the beams, sprayed FRP can do a little in strengthening the column but also can be useful to strengthen the beams. However, the resin in external bonded FRP and sprayed FRP is not fire proof. During a fire, the resin will soften and might even be burned to produce toxic gas. Therefore, additional fire prevention measures should be taken into the use of sprayed FRP reinforcement [13].

In the past, several studies on the material performance of sprayed FRP and sprayed FRP used in the reinforcement of concrete beams, columns, and masonry walls have been conducted [14-22]. The studies show that the sprayed FRP strengthening technology has good reinforcement effect and is very convenient for construction. However, the studies about sprayed FRP used in the strengthening of reinforced concrete beam-column joints are still very little.

In this paper, the research on the sprayed FRP strengthening technology used for reinforced concrete beam-column joints was carried out. The seismic performance of the strengthened joints was studied through quasi-static tests. The failure characteristics, bearing capacity, hysteretic curve, ductility, and energy dissipation were analyzed. The influence factors of the axial compression ratio, reinforcement thickness, and strengthened area were compared as well.

\section{Quasi-Static Tests}

2.1. Specimen Design and Test Variables. According to the Chinese codes Code for Design of Concrete Structures [23] and Code for Seismic Design of Buildings [24], five 1:2 reduced-scale models of RC beam-column joints controlled by shear were designed and fabricated for cyclic loading tests. Figure 1 shows the details of the joint specimens.

The joint specimens were strengthened by sprayed FRP according to the seismic design principles, which are strong column and weak beam, strong shearing and weak bend, and stronger joint. Three influencing factors were considered to design the reinforcement scheme, including the thickness of sprayed FRP, the strengthened area, and the axial compression ratio of the specimens. Table 1 gives the specific details of each tested specimen. The meaning of $X, Y$, and $Z$ is shown in Figure 2.

As can be seen from Table 1, there were five joint specimens fabricated in the test. These specimens consisted of an unreinforced specimen RCJ0 used for comparison and four strengthened specimens RCJ1, RCJ2, RCJ3, and RCJ4. RCJ1, RCJ3, and RCJ4 have the same axial compression ratio of 0.2 , while that ratio of RCJ2 is 0.4 . RCJ1, RCJ2, and RCJ4 have the same sprayed FRP thickness of $7 \mathrm{~mm}$, while that of RCJ3 is $4 \mathrm{~mm}$. RCJ1, RCJ2, and RCJ3 have the same strengthened area of $500 \mathrm{~mm}$ on beams, $450 \mathrm{~mm}$ on the upper column, and $400 \mathrm{~mm}$ on the lower column and the whole core area, while the strengthened area of RCJ4 is the whole joint surface. The strengthening diagram of test specimens is shown in Figure 2. In addition, the fiber volume ratio of the sprayed FRP used in the test was controlled to be $30 \%$ and the length of the chopped fiber was controlled to be $30 \mathrm{~mm}$. 
TABLE 1: Specific details of each tested specimen.

\begin{tabular}{lccccc}
\hline \multirow{2}{*}{ Specimen name } & Axial compression ratio & $\begin{array}{c}\text { Thickness of sprayed } \\
\text { FRP }(\mathrm{mm})\end{array}$ & \multicolumn{3}{c}{ Length of sprayed FRP } \\
& 0.2 & - & - & - & - \\
RCJ0 & 0.2 & 7 & 500 & 450 & 400 \\
RCJ1 & 0.4 & 7 & 500 & 450 & 400 \\
RCJ2 & 0.2 & 4 & Fums & 400 & 400 \\
RCJ3 & 0.2 & 7 & Full length & Lowngth & Full length \\
RCJ4 & & &
\end{tabular}

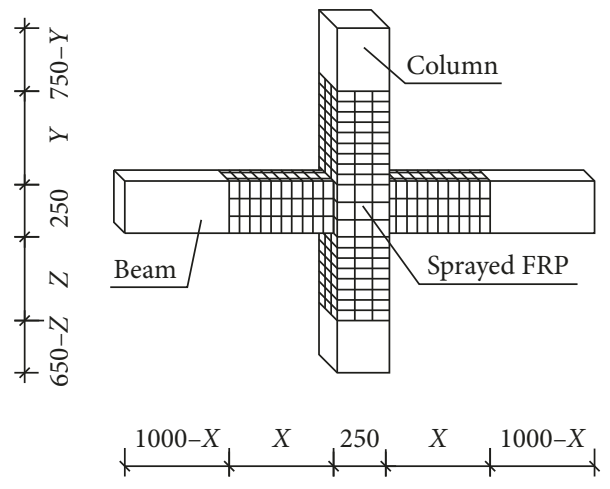

(a)

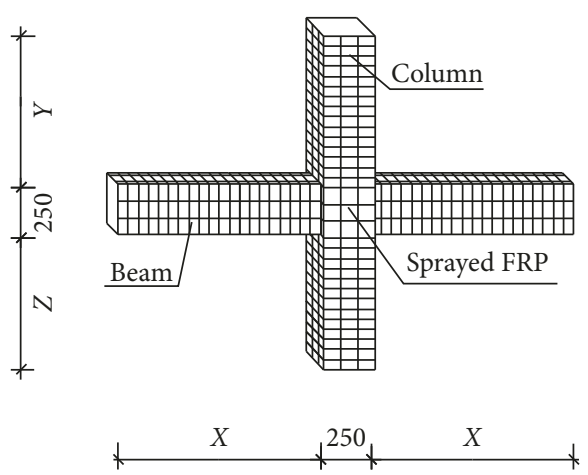

(b)

FIGURE 2: Strengthening diagram of the test specimen. (a) Partially strengthening (RJ1, RJ2, and RJ3) and (b) full-length strengthening (RJ4).

2.2. Material Properties. According to the Chinese code Code for Design of Concrete Structures [23], the concrete used in the joint specimens is C25, and the actual cube compression strength is $28.3 \mathrm{MPa}$. The longitudinal reinforcement used in the joint specimens is HRB400, and the actual yield strength is $435 \mathrm{MPa}$. The stirrup used in the joint specimens is HPB300, and the actual yield strength is $315 \mathrm{MPa}$. The reinforcement arrangement details of the joint specimen are shown in Figure 1.

E-glass fiber and vinyl ester resin 901 were used in the test to make sprayed FRP. The properties of the fiber and resin are shown in Table 2, where the values were obtained from material suppliers.

\subsection{Fabrication of Test Specimens Strengthened by Sprayed} FRP. The joint specimens were fabricated according to the Chinese code Code for Construction of Concrete Structures [25]. After the joint specimens completed, the strengthening construction was carried out through the following several steps: first, a polisher was used to make the concrete surface plain. Then, cotton yarns with acetone were used to clean the concrete surface 2 or 3 times. Then, some straight lines were drawn on the concrete surface to show the spraying area, and some small steel nails were fixed on the concrete surface to control the thickness of sprayed FRP. After that, the chopped glass fibers with vinyl ester resin were sprayed onto the concrete surface of joint specimens in the open air with the spraying equipment. After spraying, a ribbed aluminum compaction roller was used to eliminate the entrapped air voids and make the composite thickness consistent.
Finally, the strengthened joint specimens were cured for seven days in the open air at $25^{\circ} \mathrm{C}$.

2.4. Test Device and Test Method. The main purpose of this quasi-static test is to investigate the seismic behavior of the $\mathrm{RC}$ beam-column joints strengthened by sprayed FRP. The loading device is shown in Figure 3. The top of the column is connected to a $500 \mathrm{kN}$ electrohydraulic servoactuator through a holding device made of two steel plates and four long screw connectors. A hydraulic jack was put on the top end of the column to provide an axial compression load. The bottom of the column is set on the steel support through a ball hinge. The two beam ends are connected with the steel support by a steel connector with ball hinges. The electrohydraulic servoactuator is fixed on the reaction wall. The steel supports are fixed on the ground by the ground anchor screws. The connecting forms in this test device can simulate the real boundaries of an RC beam-column joint very well.

The cyclic load was applied onto the top end of the column by the electrohydraulic servoactuator. Before applying the cyclic load, the axial pressure was applied onto the top end of the column by the hydraulic jack, and the axial pressure was maintained constant during the test. When the cyclic load was applied by the actuator, the displacement control method was used to control the loading procedure. The loading process is shown in Figure 4. Before the specimen yielded, the displacement increment of each loading stage was set to be $2 \mathrm{~mm}$ and cycled one time. After the specimen yielded, the yield displacement $\Delta_{y}$ was set to be the increment for each loading stage and cycled three times at each stage. When the 
TABle 2: Properties of fiber and resin.

\begin{tabular}{|c|c|c|c|c|c|}
\hline Material name & Tensile strength $\sigma(\mathrm{MPa})$ & Elastic modulus $E(\mathrm{GPa})$ & Breaking elongation $\varepsilon(\%)$ & Poisson's ratio $\mu$ & Density $\rho\left(\mathrm{kg} / \mathrm{m}^{3}\right)$ \\
\hline E-glass fiber ${ }^{\mathrm{a}}$ & 1970 & 79 & 4.8 & 0.20 & 2550 \\
\hline $901^{\mathrm{b}}$ & 85 & 3.4 & 5.5 & 0.3 & 1050 \\
\hline
\end{tabular}

${ }^{a}$ Data from Jilin Carbon Co., Ltd., in China. ${ }^{b}$ Data from Swancor Renewable Energy Co., Ltd., in China.

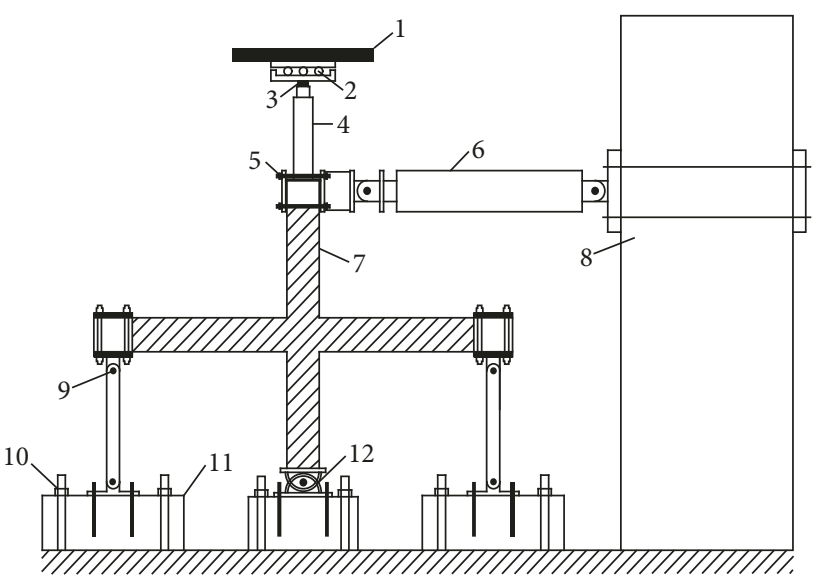

Figure 3: Loading device in the test. (1) Crossbeam, (2) movable hinge support, (3) pressure transducer, (4) lifting jack, (5) holding device, (6) servoactuator, (7) specimen, (8) reaction wall, (9) steel connector with ball hinges, (10) ground anchor screw, (11) steel support, and (12) ball hinge.

load value reduced to $85 \%$ of the peak load, the specimen was considered to be destroyed and the test was finished.

\section{Test Results}

\subsection{Failure Mode}

3.1.1. Specimen KJO. When the displacement of the column top reached $4 \mathrm{~mm}$, an initial bending crack appeared in the beam nearby the core area of the joint. When the top displacement reached $10 \mathrm{~mm}$, several inclined cracks along the two diagonals of the joint core area appeared. When the top displacement reached $20 \mathrm{~mm}$, these diagonal cracks developed to be two through cracks, and surface peeling of concrete in the joint core area was observed as well. With the applied load increasing, the through cracks became wider and the concrete cover falling became serious. Finally, the bearing capacity of the joint reduced to $85 \%$ of the peak load, and the specimen was considered to be destroyed. The failure mode was the shear failure in the core region of the joint, and this is a kind of brittle failure. The failure characteristics of KJ0 are shown in Figure 5.

3.1.2. Specimen KJ1. When the displacement of the column top reached $8 \mathrm{~mm}$, the cracking sound from the bonding interface of sprayed FRP and concrete was heard. When the top displacement reached $30 \mathrm{~mm}$, the interfacial debonding was observed in the beams. When the top displacement reached $40 \mathrm{~mm}$, the interfacial debonding was observed in

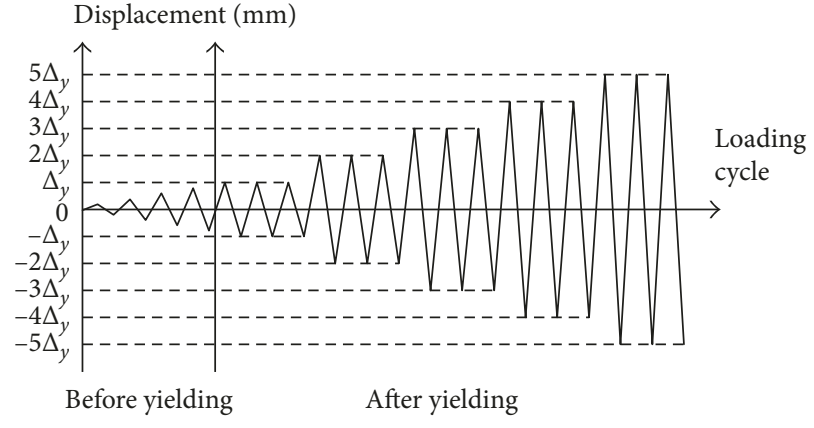

FIgURE 4: The diagram of the loading process.

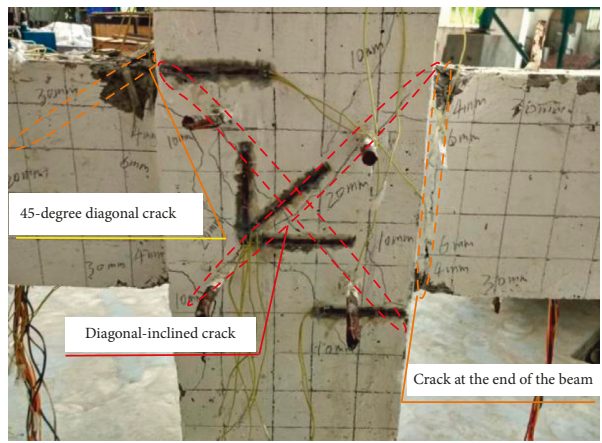

FIgURE 5: Failure characteristics of the unstrengthened specimen.

the columns. With the applied load increasing, the sprayed FRP at the intersection of beams and columns fractured. Finally, the bearing capacity of the joint declined, and the specimen was destroyed. The failure mode was the flexural failure in the beams, and this is a kind of ductile failure. The failure characteristics of the strengthened specimens are shown in Figure 6. After the test, some FRPs were cut and open to show the debonding phenomenon, which is shown in Figure 6(b).

3.1.3. Specimen KJ2. When the displacement of the column top reached $6 \mathrm{~mm}$, the cracking sound from the bonding interface of sprayed FRP and concrete was heard. When the top displacement reached $30 \mathrm{~mm}$, the interfacial debonding was observed in the beams and the columns. When the top displacement reached $40 \mathrm{~mm}$, cracks appeared in the sprayed FRP at the intersection of beams and columns. With the applied load increasing, this mentioned FRP fractured. Finally, the bearing capacity of the joint declined, and the specimen was destroyed. The failure mode was the flexural failure in the beams as well. 


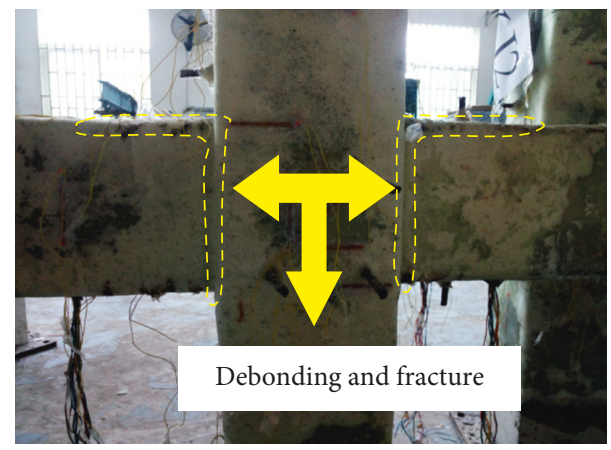

(a)
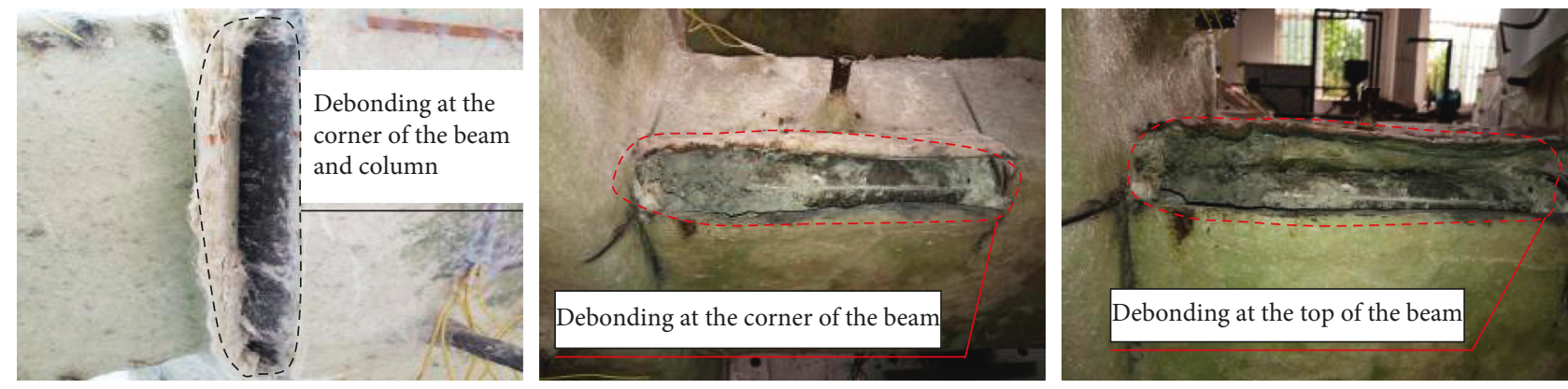

(b)

FIGURE 6: Failure characteristics of the strengthened specimen. (a) Failure mode of the specimen and (b) debonding in the cutting place.

3.1.4. Specimen KJ3. When the displacement of the column top reached $10 \mathrm{~mm}$, the cracking sound from the bonding interface of sprayed FRP and concrete was heard. When the top displacement reached $30 \mathrm{~mm}$, the interfacial debonding was observed in the beams. When the top displacement reached $40 \mathrm{~mm}$, the interfacial debonding was observed in the columns, and cracks appeared in the sprayed FRP at the intersection of beams and columns. With the applied load increasing, the FRP at the intersection of beams and columns fractured. Finally, the bearing capacity of the joint declined, and the specimen was destroyed. The failure mode was the flexural failure in the beams as well.

3.1.5. Specimen KJ4. When the displacement of the column top reached $20 \mathrm{~mm}$, the cracking sound from the bonding interface of sprayed FRP and concrete was heard. When the top displacement reached $30 \mathrm{~mm}$, the interfacial debonding was observed in the beams. When the top displacement reached $40 \mathrm{~mm}$, the interfacial debonding was observed in the columns. When the top displacement reached $50 \mathrm{~mm}$, cracks appeared in the sprayed FRP at the intersection of beams and columns. With the applied load increasing, the mentioned FRP at the intersection fractured. Finally, the bearing capacity of the joint declined, and the specimen was destroyed. The failure mode was the flexural failure in the beams as well.

The above failure processes show that the sprayed FRP can provide an effective confinement to the joint core region and increase the shear capacity of the joint core. Therefore, the failure mode of the strengthened joint can be changed from a brittle failure to a ductile failure.

3.2. Lateral Load-Displacement Hysteretic Curves and Skeleton Curves. The relationship of the lateral load and the displacement at the column top was described by hysteretic curves. All the hysteretic curves of the joint specimens are shown in Figure 7. As to KJ0, the unstrengthened joint specimen, there is a significant pinch phenomenon in the middle of the hysteretic curve. The shape of this hysteretic curve is like a letter " $S$ " lying on the floor. As to the strengthened specimens, the hysteretic curves are plumper than those of $\mathrm{KJ0}$, and the pinch phenomenon is not as serious as that of KJ0, showing a better energy dissipation capacity. But to $\mathrm{KJ} 2$, its axial compression ratio is 0.4 , which is more than that of other specimens. Its hysteretic curve is plump, but the maximum displacement is smaller than that of the unstrengthened specimen.

The skeleton curves of each joint specimen are shown together in Figure 8. Compared with the unreinforced specimen KJ0, the ultimate load and the initial stiffness of the strengthened specimens are significantly increased. Especially the specimen $\mathrm{KJ} 2$ with an axial compression ratio 0.4 has the maximum ultimate load and initial stiffness. As to the ultimate displacement, $\mathrm{KJ} 1, \mathrm{KJ} 3$, and $\mathrm{KJ} 4$ are larger than $\mathrm{KJ} 0$, but $\mathrm{KJ} 2$ is smaller than KJ0.

The above phenomenon shows that sprayed FRP strengthening can effectively improve the seismic capacity of $\mathrm{RC}$ beam-column joints. The increase of the axial compression 


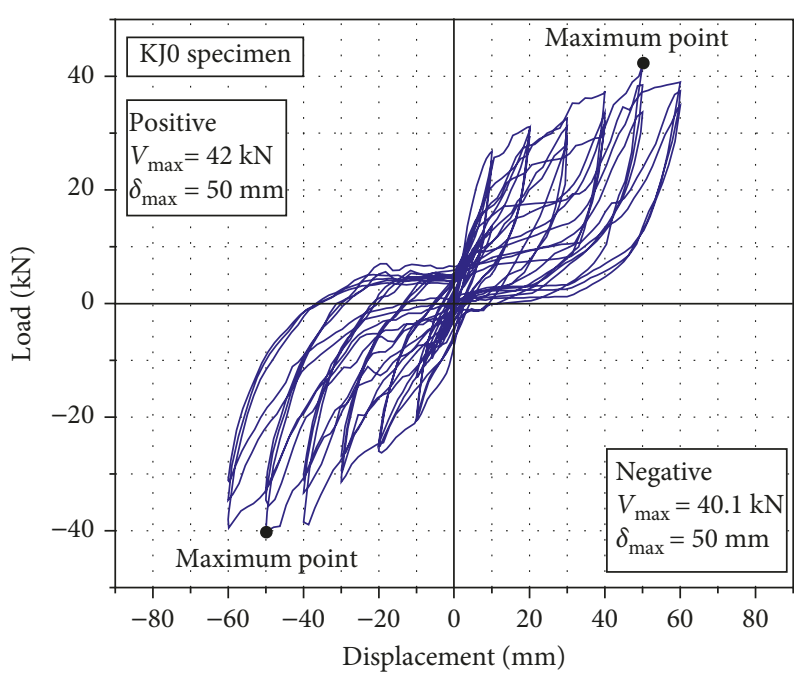

(a)

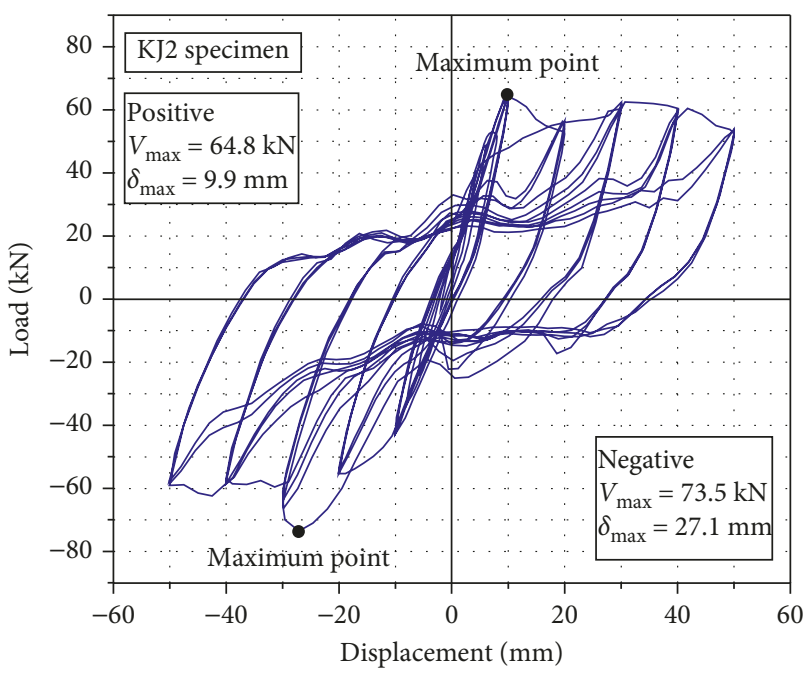

(c)

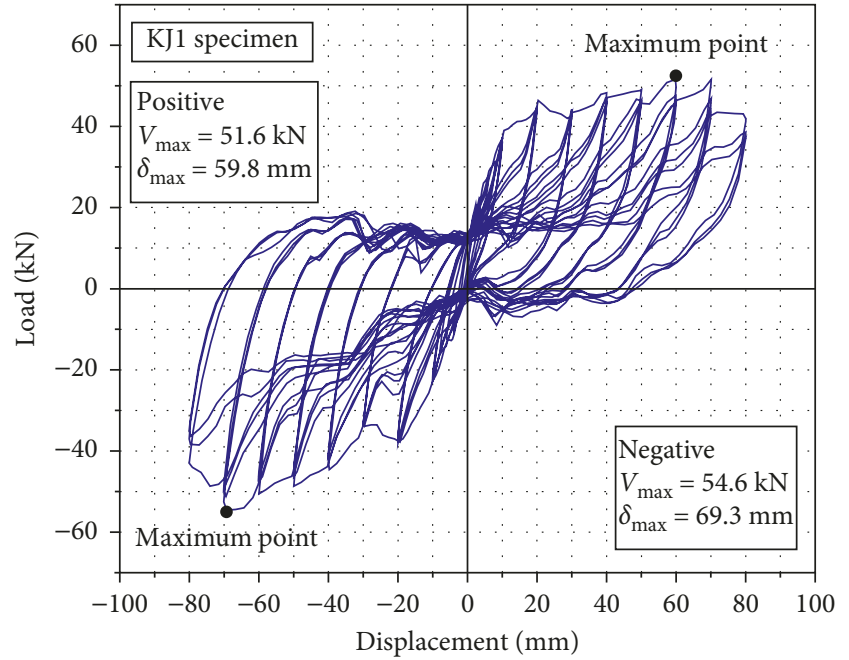

(b)

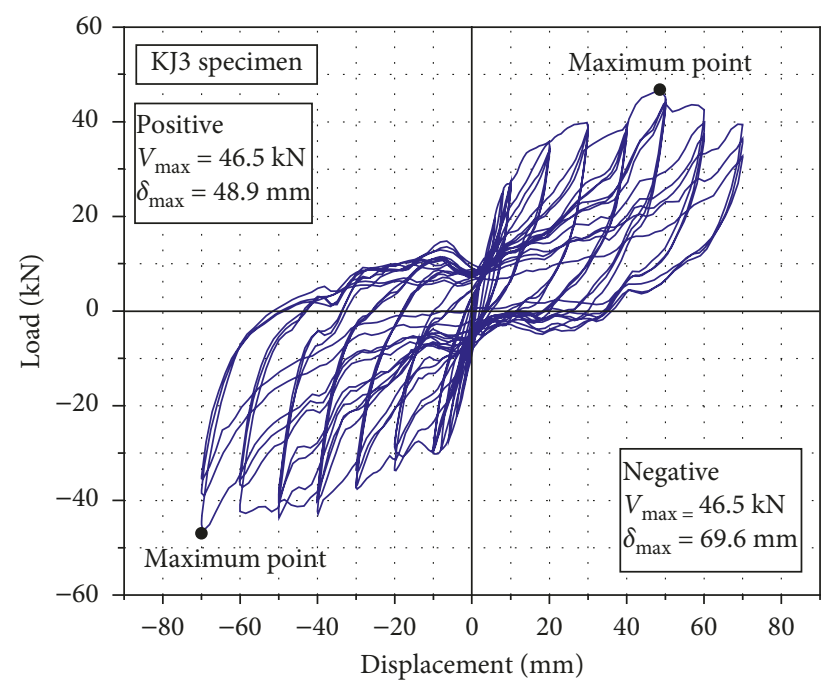

(d)

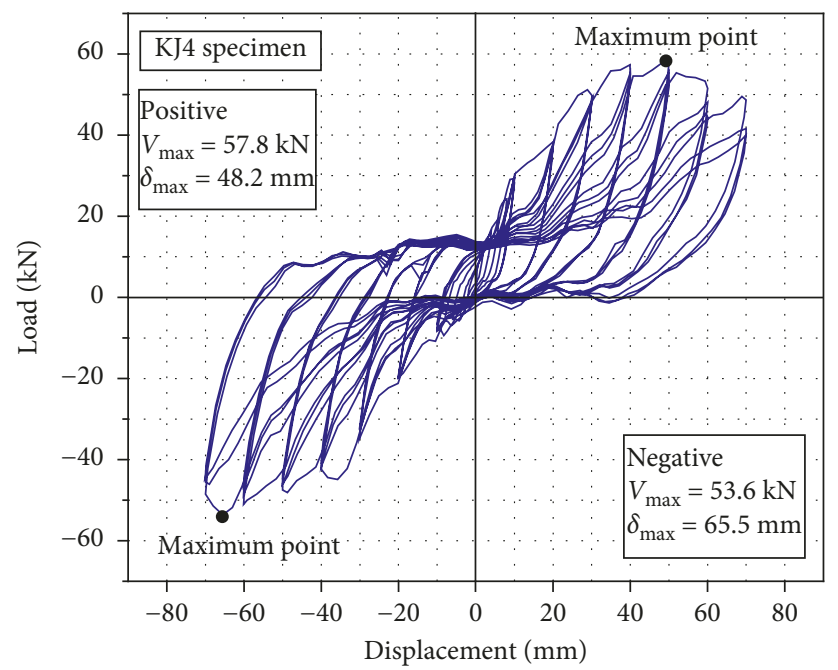

(e)

Figure 7: Hysteretic curves. (a) KJ0, (b) KJ1, (c) KJ2, (d) KJ3, and (e) KJ4. 


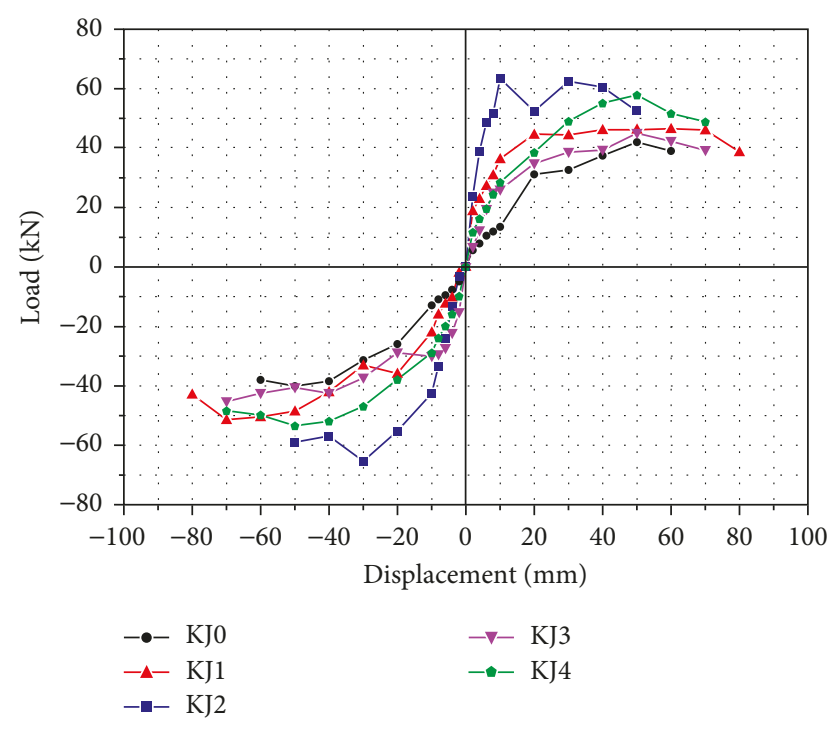

FIGURE 8: Skeleton curves.

ratio can significantly increase the stiffness and bearing capacity of RC joints, but it will decrease their ductility.

3.3. Strength and Deformation. In the test, we take the lateral peak load applied on the column top as the ultimate load for the joint specimen. In the meantime, the lateral displacement of the top column corresponding to the applied load decreasing to $85 \%$ peak load was assumed to be the ultimate displacement for the joint specimen. The values of the ultimate load and ultimate displacement of the tested specimens are listed in Table 3. In Table 3, "pushing" and "pulling" stand for the two loading directions in the cyclic loading. The "average" means the average value of pushing and pulling loads. The "increasing ratio" stands for the increasing percentage when the value of a strengthened specimen is compared with the value of the unstrengthened specimen KJO.

From Table 3, the ultimate loads of the reinforced specimens are larger than those of the unreinforced specimen KJ0 significantly. The maximum ultimate load belongs to $\mathrm{KJ} 2$ with the highest average increasing ratio of $72 \%$. The lowest average increasing ratio of the ultimate load is $13 \%$ and belongs to KJ3. The ultimate displacements of the reinforced specimens except KJ2 are larger than those of the unreinforced specimen KJ0 as well. The maximum ultimate displacement belongs to KJ1 with the highest average increasing ratio of $33 \%$. The lowest average increasing ratio of the ultimate displacement is $17 \%$ and belongs to $\mathrm{KJ} 3$ and $\mathrm{KJ} 4$.

Analyzing the influencing factors, we can get some results as follows. As to the axial compression ratio, KJ2 with an axial compression ratio of 0.4 was compared with $\mathrm{KJ} 1$ with an axial compression ratio of 0.2 , and they are the same in the other influencing factors. With the increase of the axial compression ratio, the ultimate load has greatly improved, while the ultimate displacement has decreased significantly. As to the reinforcement thickness, KJ3 with a thickness of $4 \mathrm{~mm}$ was compared with $\mathrm{KJ} 1$ with a thickness of $7 \mathrm{~mm}$, and they are the same in the other influencing factors. With the decrease of the reinforcement thickness, the ultimate load and displacement are both decreased as well. As to the reinforcement area, KJ4 with full-length reinforced was compared with KJ1 with partially reinforced, and they are the same in the other influencing factors. With the increase of the reinforcement area, the ultimate load increased a little, while the ultimate displacement decreased obviously.

3.4. Degradation of Strength. In the cyclic loading test for concrete structures, the maximum applied load in each cycle will decrease with the increase of cycle times, although the loading displacement remains the same. This characteristic of structures is called the degradation of strength. In order to study the strength degradation of joint specimens, the strength degradation index $\lambda$ was used in this paper. The index $\lambda$ means the ratio of the maximum load in a certain loading cycle to the maximum load in the previous loading cycle, when the loading displacement of the two cycles remains the same, which is shown as follows:

$$
\lambda=\frac{P_{i, \max }}{P_{i-1, \max }},
$$

where $P_{i, \max }$ is the maximum load of the $i$ th loading cycle and $P_{i-1, \max }$ is the maximum load of the $(i-1)$ th loading cycle.

The value of $\lambda$ for each loading cycle after specimen yielding was calculated according to (1) and listed in Table 4. From Table 4, it can be seen that the strength degradation speed of the specimens strengthened by sprayed FRP is obviously slower than that of the unreinforced specimen.

3.5. Degradation of Stiffness. Stiffness degradation means that the stiffness of a structure specimen under cyclic loading will decrease with the increase of cycle times and structure deformation. The secant stiffness $K$ is used in this paper to calculate the stiffness of the joint specimens. In a certain loading cycle, $K$ can be obtained from the following [24]:

$$
K=\frac{\left(\left|P_{i+\max }\right|+\left|P_{i-\max }\right|\right)}{\left(\left|\Delta_{i+\max }\right|+\left|\Delta_{i-\max }\right|\right)},
$$

where $P_{i+\max }$ and $\Delta_{i+\max }$ mean the positive maximum load and its displacement, respectively, and $P_{i-\max }$ and $\Delta_{i-\max }$ mean the negative maximum load and its displacement, respectively.

The secant stiffness values of the specimens in the first cycle for each loading displacement are calculated according to (2). The relationship curves of the secant stiffness and the loading displacement are shown in Figure 9.

From Figure 9, it can be concluded as follows: firstly, the initial stiffness of the joint specimens strengthened by sprayed FRP increased significantly, but the stiffness degradation was faster than that of the unreinforced one. Secondly, when the axial compression ratio is no more than 0.4 , the specimen's initial stiffness increased significantly with the increase of the axial compression ratio, but the stiffness degraded significantly as well. Thirdly, the increase 
TABLE 3: Values of the ultimate load and ultimate displacement of the tested specimens.

\begin{tabular}{|c|c|c|c|c|c|c|c|c|}
\hline \multirow{2}{*}{$\begin{array}{l}\text { Specimen } \\
\text { name }\end{array}$} & \multicolumn{4}{|c|}{ Ultimate load } & \multicolumn{4}{|c|}{ Ultimate displacement } \\
\hline & $\begin{array}{c}\text { Pushing } \\
(\mathrm{kN})\end{array}$ & $\begin{array}{c}\text { Pulling } \\
(\mathrm{kN})\end{array}$ & $\begin{array}{c}\text { Average } \\
(\mathrm{kN})\end{array}$ & $\begin{array}{c}\text { Increasing ratio } \\
(\%)\end{array}$ & $\begin{array}{l}\text { Pushing } \\
\text { (mm) }\end{array}$ & $\begin{array}{l}\text { Pulling } \\
\text { (mm) }\end{array}$ & $\begin{array}{c}\text { Average } \\
(\mathrm{mm})\end{array}$ & $\begin{array}{c}\text { Increasing ratio } \\
(\%)\end{array}$ \\
\hline KJ0 & 42 & 41.5 & 41.8 & - & 60 & 60 & 60 & - \\
\hline KJ1 & 52.8 & 54.6 & 53.7 & 29 & 80 & 80 & 80 & 33 \\
\hline $\mathrm{KJ} 2$ & 70.3 & 73.5 & 71.9 & 72 & 50 & 50 & 50 & - \\
\hline $\mathrm{KJ} 3$ & 46.5 & 46.5 & 46.5 & 12 & 70 & 70 & 70 & 17 \\
\hline KJ4 & 57.8 & 53.6 & 55.7 & 34 & 70 & 70 & 70 & 17 \\
\hline
\end{tabular}

TABLE 4: Values of $\lambda$ for each loading cycle.

\begin{tabular}{lcccccccc}
\hline \multirow{2}{*}{ Specimen } & \multicolumn{9}{c}{ Displacement } \\
& $\Delta_{y}$ & $2 \Delta_{y}$ & $3 \Delta_{y}$ & $4 \Delta_{y}$ & $5 \Delta_{y}$ & $6 \Delta_{y}$ & $7 \Delta_{y}$ & - \\
\hline KJ0 & 0.989 & 0.974 & 0.955 & 0.931 & 0.901 & 0.857 & - \\
KJ1 & 0.991 & 0.982 & 0.973 & 0.964 & 0.946 & 0.934 & 0.941 \\
KJ2 & 0.994 & 0.985 & 0.969 & 0.954 & 0.930 & - & - \\
KJ3 & 0.990 & 0.980 & 0.976 & 0.954 & 0.945 & 0.921 & 0.886 \\
KJ4 & 0.995 & 0.988 & 0.972 & 0.970 & 0.939 & 0.918 & - \\
\hline
\end{tabular}

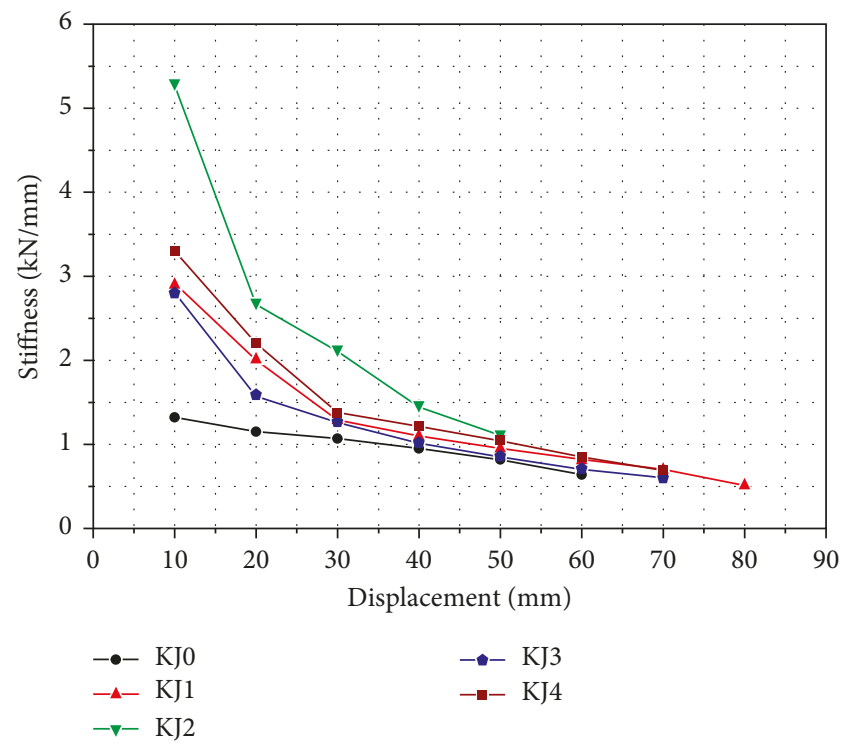

Figure 9: Stiffness degradation of the specimens.

of the sprayed FRP thickness can increase the specimen stiffness a little, while the increase of the strengthening area seemed to have no obvious effect on the stiffness. The last, when the joint specimen was nearing the ultimate condition, the stillness of all the specimens including the strengthened ones and unstrengthened one tended to be the same.

3.6. Ductility and Energy Dissipation Capacity. Ductility is an important index to evaluate the seismic performance of structure members. Better ductility means better seismic performance. The displacement ductility coefficient $\mu$ is used to evaluate the seismic performance of the joint specimens in this paper. The equation of $\mu$ is as follows:

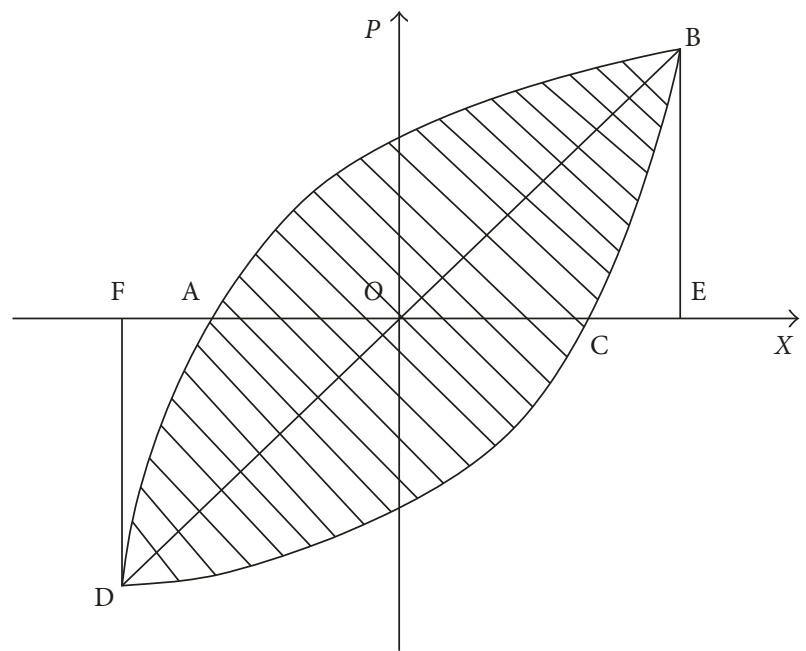

FIgure 10: Calculating diagram of $h_{e}$.

$$
\mu=\frac{\Delta_{\mu}}{\Delta_{y}}
$$

where $\Delta_{\mu}$ means the ultimate displacement and $\Delta_{y}$ means the yield displacement.

Energy dissipation capacity is another important index to evaluate the seismic performance of structure members. Better energy dissipation capacity can make the seismic behavior of structure members better as well. The equivalent viscous damping coefficient [26] $h_{e}$ is used in this paper to measure the energy dissipation capacity of the joint specimens. The equation of $h_{e}$ is as follows:

$$
h_{e}=\frac{1}{2 \pi} \times \frac{S_{(\mathrm{ABC}+\mathrm{CDA})}}{S_{(\mathrm{OBE}+\mathrm{ODF})}}
$$

where $S_{(\mathrm{ABC}+\mathrm{CDA})}$ and $S_{(\mathrm{OBE}+\mathrm{ODF})}$ are some areas that come from the calculated cycle of the lateral load-displacement 
Table 5: Values of coefficients $\mu$ and $h_{e}$ of each specimen.

\begin{tabular}{lcccc}
\hline Specimen & Yield displacement $\Delta_{y}(\mathrm{~mm})$ & Ultimate displacement $\Delta_{u}(\mathrm{~mm})$ & Coefficient $\mu$ & Coefficient $h_{e}$ \\
\hline KJ0 & 13.2 & 60 & 4.55 & 0.1956 \\
KJ1 & 10 & 80 & 7.04 & 0.2413 \\
KJ2 & 7.1 & 50 & 6.03 & 0.2723 \\
KJ3 & 11.6 & 70 & 8.24 & 0.2196 \\
KJ4 & 8.5 & 70 & 0.2491 \\
\hline
\end{tabular}

hysteretic curve, which is shown in Figure 10. The loading cycle just before the specimen destroyed was used in this paper to calculate $h_{e}$ by using the software Origin.

The coefficients $\mu$ and $h_{e}$ of each specimen are shown in Table 5. From Table 5, we can draw some conclusions as follows: firstly, the sprayed FRP strengthening technology can improve the ductility and energy dissipation capacity of joint specimens effectively because the values of $\mu$ and $h_{e}$ of all the strengthened specimens are larger than those of the unreinforced one. Secondly, the increase of the sprayed FRP thickness can increase the ductility and energy dissipation capacity of RC beam-column joints because the values of $\mu$ and $h_{e}$ of KJ1 with the FRP thickness of $7 \mathrm{~mm}$ are much bigger than those of KJ3 with the FRP thickness of $4 \mathrm{~mm}$. Thirdly, the increase of the strengthening area can just increase a little of the ductility and energy dissipation capacity of RC beam-column joints because the values of $\mu$ and $h_{e}$ of $\mathrm{KJ} 4$ with full-length strengthened increased just a little than those of KJ1 with partially strengthened. The last, the increase of the axial compression can increase the energy dissipation capacity of joint specimens, when the axial compression ratio is no more than 0.4. However, the ductility will be decreased to some extent because KJ2 with the highest axial compression ratio has the maximum $h_{e}$ of 0.2723 , while its $\mu$ is smaller than that of $\mathrm{KJ} 1$ and $\mathrm{KJ} 4$ with an axial compression ratio of 0.2 .

\section{Summary and Conclusions}

This paper has studied the seismic performance of the RC beam-column joints strengthened with sprayed FRP. Through the quasi-static tests for five joint specimens, the failure mode, lateral load-displacement hysteretic curves and skeleton curves, strength and deformation, degradation of strength and stiffness, and ductility and energy dissipation capacity were studied. In addition, three main influencing factors were compared as well. The conclusions can be drawn as follows:

(1) Sprayed FRP strengthening can improve the seismic behavior of RC beam-column joints effectively. The continuous reinforcement layer of sprayed FRP can provide effective confinement to the core zone of the RC beam-column joint.

(2) The increase of the sprayed FRP thickness can improve the bearing capacity, deformation capacity, and energy dissipation capacity of RC beam-column joints significantly. In addition, the ductility and initial stiffness of the joints can be improved as well.

(3) The increase of the strengthening area is very effective in improving the bearing capacity, but it has just a little effect in improving the deformation capacity, energy dissipation capacity, ductility, and initial stiffness of RC beam-column joints.

(4) Under a certain value, the increase of the axial compression ratio can significantly improve the bearing capacity and initial stiffness of RC beam-column joints but will decrease the deformation capacity and ductility. However, due to the plumper hysteretic curve, it can increase the energy dissipation capacity as well.

\section{Conflicts of Interest}

The authors declare that there are no conflicts of interest regarding the publication of this paper.

\section{Acknowledgments}

This research received specific grants from the Natural Science Foundation of China and the Research Foundation of Wuhan Construction Committee.

\section{References}

[1] S. S. Mahini and H. R. Ronagh, "Strength and ductility of FRP web-bonded RC beams for the assessment of retrofitted beam-column joints," Composite Structures, vol. 92, no. 6, pp. 1325-1332, 2010.

[2] K. Amin, "Investigation on the effects of L-shaped FRPs for strengthening of exterior RC joints to relocate the plastic hinge place away from the column face," International Journal of Advances in Engineering Sciences, vol. 3, no. 2, pp. 13-18, 2013.

[3] A. Pankaj, A. Gupta, and R. G. Angadi, "Effect of FRP wrapping on axial behavior of concrete and cyclic behavior of external RC beam column joints," KSCE Journal of Civil Engineering, vol. 18, no. 2, pp. 566-573, 2014.

[4] R. Realfonzo, A. Napoli, and J. G. R. Pinilla, "Cyclic behavior of RC beam-column joints strengthened with FRP systems," Construction and Building Materials, vol. 54, no. 15, pp. 282297, 2014

[5] B. Antonio, F. Francesco, P. L. Gian, P. Andrea, and M. Gaetano, "Simplified model for strengthening design of beam-column internal joints in reinforced concrete frames," Polymers, vol. 7, no. 9, pp. 1732-1754, 2015.

[6] E. Z. Beydokhty and H. Shariatmadar, "Behavior of damaged exterior RC beam-column joints strengthened by CFRP composites," Latin American Journal of Solids and Structures, vol. 13, no. 5, pp. 880-896, 2016.

[7] M. R. Javanmardi and M. R. Maheri, "Anisotropic damage plasticity model for concrete and its use in plastic hinge relocation in RC frames with FRP," Structures, vol. 12, pp. 212226, 2017. 
[8] E. Esmaeeli, F. Danesh, K. F. Tee, and S. Eshghi, "A combination of GFRP sheets and steel cage for seismic strengthening of shear-deficient corner RC beam-column joints," Composite Structures, vol. 159, no. 1, pp. 206-219, 2017.

[9] Z. Yang and K. Wu, "Experimental analysis of tensile mechanical properties of sprayed FRP," Advances in Materials Science and Engineering, vol. 2016, Article ID 3514830, 12 pages, 2016.

[10] A. J. Boyd, "Rehabilitation of reinforced concrete beams with sprayed glass fiber reinforced polymers," Ph.D. thesis, University of British Columbia, Vancouver, BC, Canada, 2000.

[11] H. K. Lee, "Effectiveness of anchorage in concrete beams retrofitted with sprayed fiber-reinforced polymers," Journal of Reinforced Plastics and Composites, vol. 23, no. 12, pp. 12851300, 2004.

[12] Z. Yang and C. Wu, "Analysis on the seismic performance of RC frame beam-column joints strengthened by sprayed FRP," Applied Mechanics and Materials, vol. 578-579, pp. 835-838, 2014.

[13] G. F. Ji, G. Q. Li, and W. Alaywan, "A new fire resistant FRP for externally bonded concrete repair," Construction and Building Materials, vol. 42, pp. 87-96, 2013.

[14] S. M. Soleimani, "Sprayed glass fibre reinforced polymers in shear strengthening and enhancement of impact resistance of reinforced concrete beams," Ph.D. thesis, University of British Columbia, Vancouver, BC, Canada, 2006.

[15] A. J. Boyd, N. F. Liang, P. S. Green, and K. Lammert, "Sprayed FRP repair of simulated impact in prestressed concrete girders," Construction and Building Materials, vol. 22, no. 3, pp. 411-416, 2008.

[16] S. K. Ha, S. Na, and H. K. Lee, "Bond characteristics of sprayed FRP composites bonded to concrete substrate considering various concrete surface conditions," Composite Structures, vol. 100, pp. 270-279, 2013.

[17] K. S. Lee, B. Y. Lee, and S. Y. Seo, "A seismic strengthening technique for reinforced concrete columns using sprayed FRP," Polymers, vol. 8, no. 4, pp. 1-21, 2016.

[18] Q. Gu, G. Dong, B. M. Getahune, and X. Wang, "Test of seismic performance of earthquake damaged reinforced concrete columns strengthened with sprayed FRP," Fuhe Cailiao Xuebao, vol. 33, no. 5, pp. 1009-1019, 2016.

[19] S. K. Ha, S. Na, Y. K. Bang, and H. K. Lee, "An experimental study on sag-resistance ability and applicability of sprayed FRP system on vertical and overhead concrete surfaces," Materials and Structures, vol. 48, no. 1-2, pp. 21-33, 2015.

[20] K. S. Lee, "Experimental study on sprayed FRP system for strengthening reinforced concrete beams," Journal of Advanced Concrete Technology, vol. 10, no. 6, pp. 219-230, 2012.

[21] S. K. Ha, H. R. Khalid, S. M. Park, and H. K. Lee, "Interfacial crack-induced debonding behavior of sprayed FRP laminate bonded to RC beams," Composite Structures, vol. 128, pp. 176-187, 2015.

[22] S. M. Soleimani and N. Banthia, "Shear strengthening of RC beams using sprayed glass fiber reinforced polymer," Advances in Civil Engineering, vol. 2012, Article ID 635176, 20 pages, 2012.

[23] GB 50010-2010, Code for Design of Concrete Structures, 2015.

[24] GB 50011-2010, Code for Seismic Design of Buildings, 2010.

[25] GB 50666-2011, Code for Construction of Concrete Structures, 2011.

[26] JGJ/T 101-2015, Specification for Seismic Test of Buildings, 2015. 


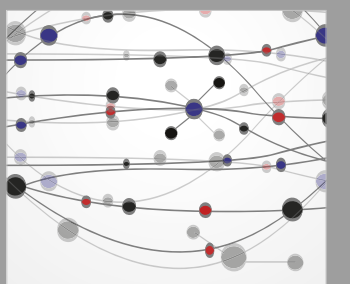

The Scientific World Journal
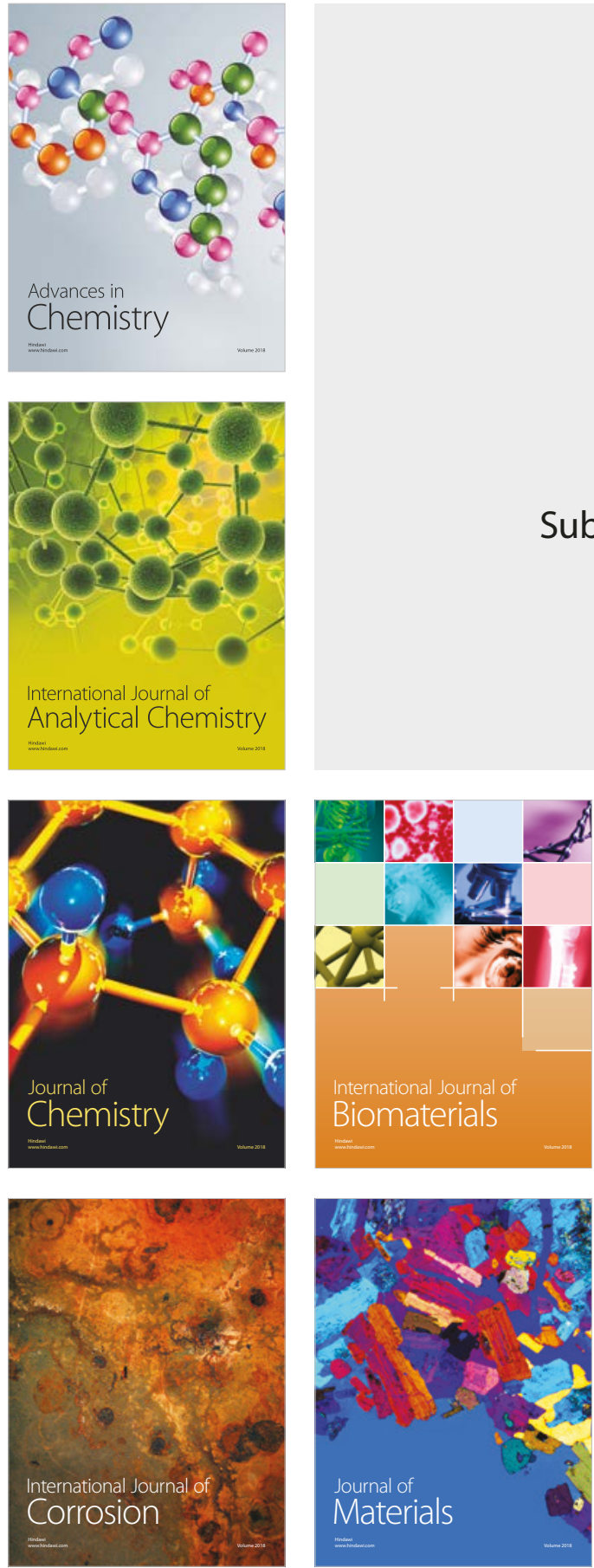

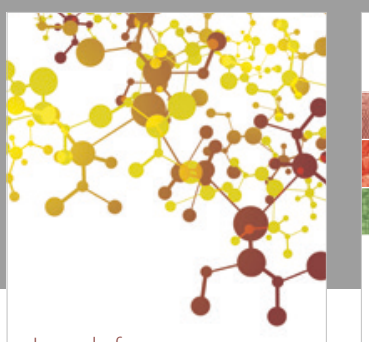

Journal of

Applied Chemistry
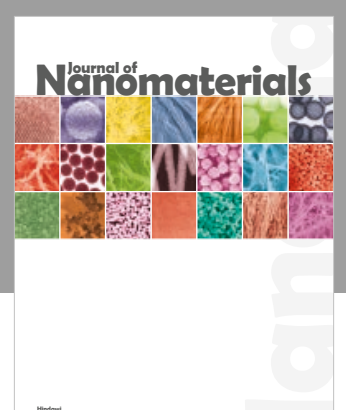

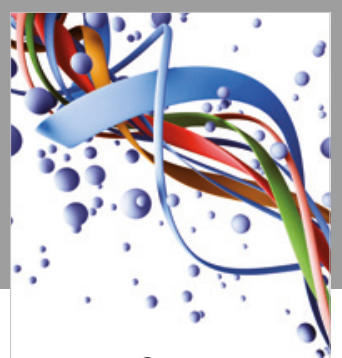

Scientifica

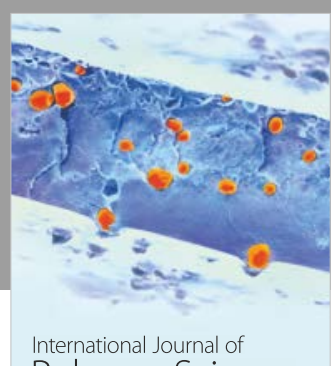

Polymer Science

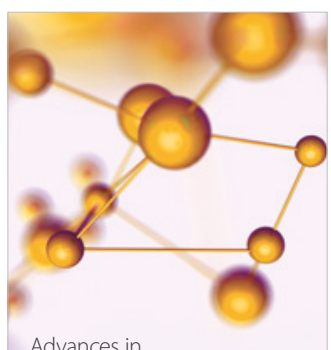

Physical Chemistry
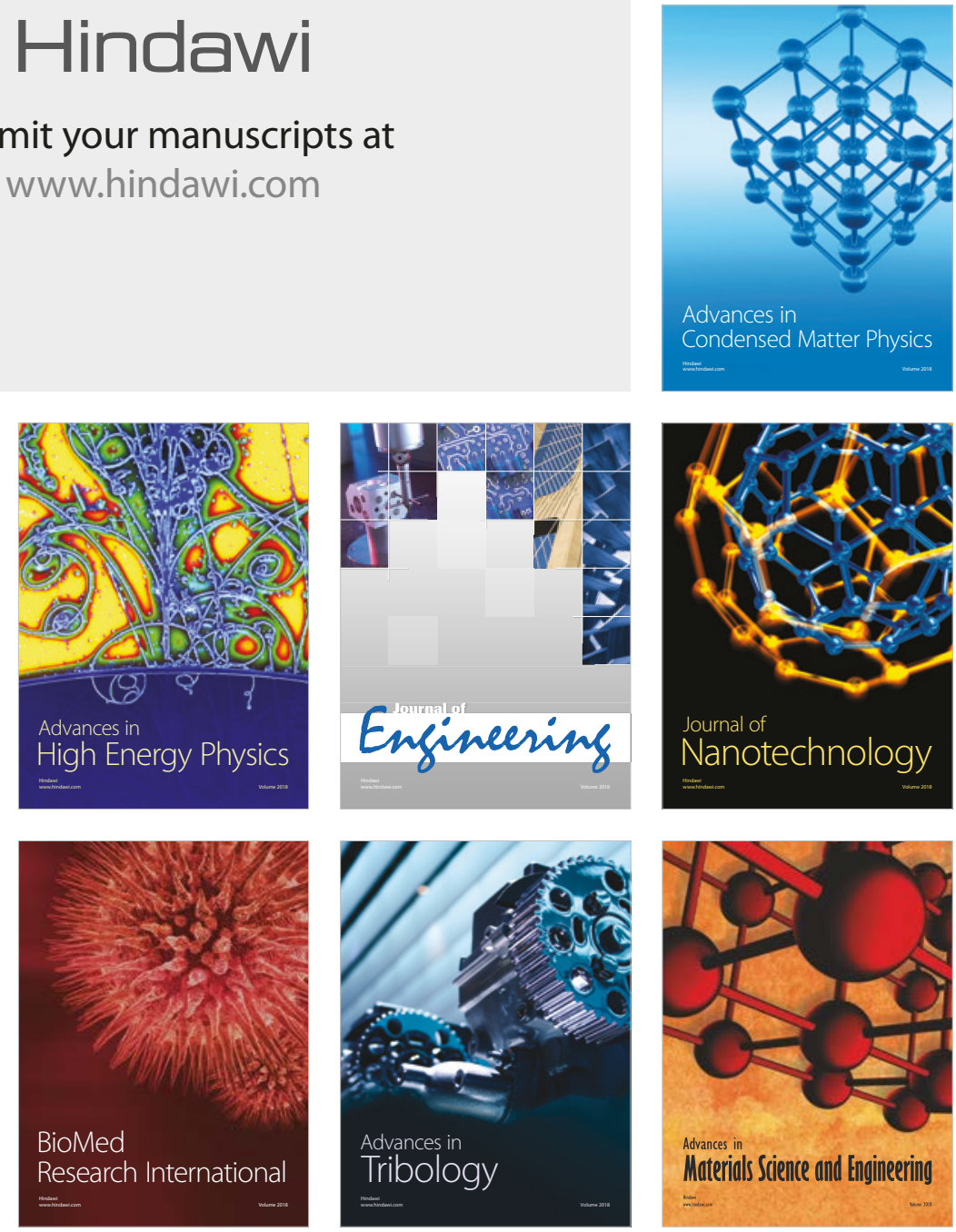